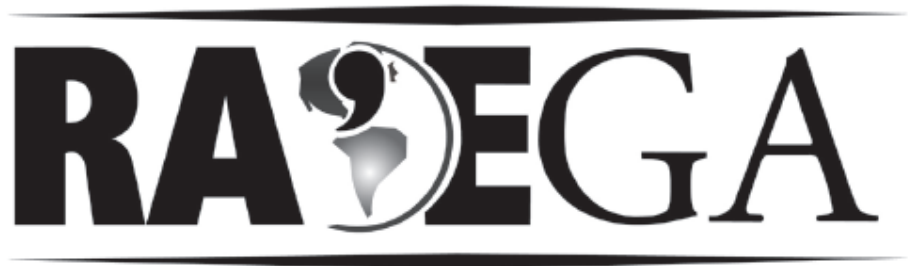

O ESPAÇO GEOGRÁFICO EM ANÁLISE

\title{
A PERCEPÇÃO CLIMÁTICA DA POPULAÇÃO URBANA DE SANTA CRUZ DO SUL/RS ${ }^{1}$
}

\section{THE CLIMATIC PERCEPTION OF URBAN POPULATION OF SANTA CRUZ DO SUL/RS}

\author{
Diamar Ruoso $^{2}$
}

\section{RESUMO}

Neste estudo buscou-se avaliar qualitativamente o grau de percepção climática dos indivíduos que vivem no meio urbano de Santa Cruz do Sul - RS, colaborando com os estudos de percepção ambiental. A metodologia constituiu-se de caracterização da área de estudo e na abordagem da percepção climática inspirada na metodologia proposta por Sartori (2000). Foram entrevistadas 128 pessoas, que responderam a várias perguntas, dentre elas, ditados populares ou observações pessoais para prever os fenômenos atmosféricos futuros. A população mostrou, no geral, respostas perceptivas relevantes, ficando evidenciada a percepção ambiental e climática, resgatando o conhecimento popular, muito rico em experiências no espaço vivido.

Palavras-chaves: percepção ambiental; percepção climática; cognição ambiental.

\footnotetext{
${ }^{1}$ Este trabalho é uma parte da dissertação de mestrado da autora intitulado "O Clima de Santa Cruz do Sul - RS e a Percepção Climática da População Urbana", apresentado no Curso de Mestrado do Programa de Pós-Graduação em Geografia, Área de Concentração em Análise Ambiental e Dinâmica Espacial, da Universidade Federal de Santa Maria (UFSM, RS) tendo como orientadora a professora Dr ${ }^{\underline{a}}$ Maria da Graça Barros Sartori.

${ }^{2}$ Mestre em Geografia pelo Programa de Pós-Graduação em Geografia da Universidade Federal de Santa Maria/RS - UFSM/RS. <druoso@gmail.com>
} 


\section{ABSTRACT}

This study aimed to evaluate qualitatively the degree of climatic perception of the urban inhabitants of Santa Cruz do Sul - RS, collaborating with the studies of environmental perception. The methodology consisted of characterization of the study area and in the approach to climatic perception inspired by the method proposed by Sartori (2000). We surveyed 128 people who answered several questions, among them, popular sayings or personal observations to predict future atmospheric phenomena. The population showed, in general, relevant perceptual responses, being evident environmental and climate perception, rescuing folk knowledge, rich experiences in the lived space

Keywords: environmental perception; climatic perception; environmental cognition.

\section{INTRODUÇÃO}

A percepção vincula-se diretamente ao ambiente, entendido como resultado da interação da sociedade com a natureza, de forma indissociável, pois as condições e/ou alterações do meio natural só têm importância para o homem quando passam a ser por ele percebidas ou quando afetam o seu bem estar e o seu modo de vida. Tuan (1980) diz que o homem percebe o mundo através dos órgãos sensitivos que, levando em conta também sua experiência, são exercitados, variando com a cultura e com a realidade de cada um, pois a cultura afeta a percepção. Essa realidade em que o indivíduo está inserido, sua convivência e assimilação do que é percebido em seu entorno é chamado de cognição, que Machado (1998, p. 02) diz ser "O processo mental mediante o qual, a partir do interesse e da necessidade, estruturamos e organizamos nossa interface com a realidade e o mundo, selecionamos as informações percebidas armazenando-as e conferindo-Ihes significado".

A percepção também pode ser analisada dentro de um contexto ambiental, na qual Faggionato (2005) coloca que a percepção ambiental foi definida como sendo "uma tomada de consciência do ambiente pelo homem". Essa consciência pode-se dar pelo clima, por exemplo, pois "[...] o problema de como os indivíduos percebem o clima é a parte principal no campo da percepção ambiental" (SARTORI, 2000, P.35). 
A percepção climática apresenta dois enfoques: um, a respeito da percepção do tempo, outro, a percepção psico-fisiológica. Este trabalho voltase ao estudo da percepção do tempo. Nota-se que na percepção climática, o homem

\footnotetext{
Através de ajustamentos fisiológicos e comportamentais, 0 homem é notavelmente adaptável a seu ambiente. As mudanças climáticas cíclicas influenciam os ritmos biológicos, os quais interferem em todas as atividades e funções humanas. Porém, os seres humanos mostram variações individuais muito grandes em sua adaptabilidade, o que interfere na sua maior ou menor sensibilidade ao tempo e ao clima, e dessa forma, em seu conforto e saúde (SARTORI, 2000, p. 60).
}

Esse enfoque de estudo, segundo Christofoletti (2005), vem se desenvolvendo desde 1970 com o surgimento da Geografia Humanística abordada por Yi-Fu Tuan, Buttimer, Edward Relph, Mercer e Powell, tendo a fenomenologia existencial como a filosofia subjacente, que se define como sendo uma filosofia que descreve um fenômeno a partir da percepção e experiência manifestada pelos indivíduos que convivem com o fenômeno, no tempo e no espaço, e o interpretam segundo as leis do seu conhecimento ou da sua consciência (ENTRIKIN, 1976).

Historicamente, o estudo da percepção climática ainda é recente no Brasil, visto que o primeiro trabalho foi realizado por Sartori (2000) como tese de doutorado pela Universidade de São Paulo (USP). A metodologia proposta por Sartori para o estudo da percepção climática orienta o desenvolvimento deste trabalho.

Como objetivo geral para este estudo, buscou-se avaliar qualitativamente o grau de percepção climática dos indivíduos que vivem no meio urbano de Santa Cruz do Sul - RS, colaborando com o desenvolvimento dos estudos de percepção ambiental. Para isso, foram estabelecidos como objetivos específicos mais importantes: caracterizar geograficamente a cidade de Santa Cruz do Sul - RS; avaliar a percepção do clima urbano pela população da cidade de Santa Cruz do Sul - RS, em função das componentes geourbanas modificadoras das características climáticas na escala local; 
entender a relação homem urbano-clima, buscando identificar diferenças e semelhanças de percepção em função de fatores individuais, culturais e sociais.

\section{METODOLOGIA}

A metodologia adotada foi desenvolvida com relação à abordagem da percepção climática. Mas para isso, inicialmente, buscou-se compreender a dinâmica atmosférica regional que ocorrem em Santa Cruz do Sul, bem como os elementos que se interrelacionam no interior da cidade para definir o clima urbano.

Para realizar a pesquisa segundo uma abordagem qualitativa como a da percepção, em vez de mera quantificação de dados deve-se dar atenção, também, aos dados levantados no contexto social onde os eventos acontecem do ponto de vista dos indivíduos entrevistados. A coleta de dados incluiu assim "procedimentos e instrumentos subjetivos na situação de campo, preocupandose com a descoberta e descrição" de fatos (SARTORI, 2000, p. 150), passíveis de observação e verificação a campo, ocorrendo paralelamente à aplicação das entrevistas. Por isso, a abordagem perceptiva dos indivíduos requer certo cuidado, pois segundo Machado (1988), é uma tarefa difícil e delicada, uma vez que se deve prestar atenção aos significados/complexidades que as pessoas dão ao tempo meteorológico, por exemplo, em uma descrição simples (leiga) do que se pretende investigar.

Com a estratégia de pesquisa definida, buscou-se atender as necessidades de averiguação da percepção ambiental e climática entre os habitantes do meio urbano, levando em conta o juízo de valores determinados pela experiência individual dos moradores quanto ao tempo atmosférico, aprofundando o levantamento de informações sobre a percepção do tempo e do clima urbano.

$\mathrm{Na}$ adequada utilização desse instrumento a população, Sartori (2000, p. 160) estabeleceu variáveis que devem ser consideradas na seleção dos 
indivíduos, das quais algumas foram utilizadas em função dos objetivos desse trabalho. São elas:

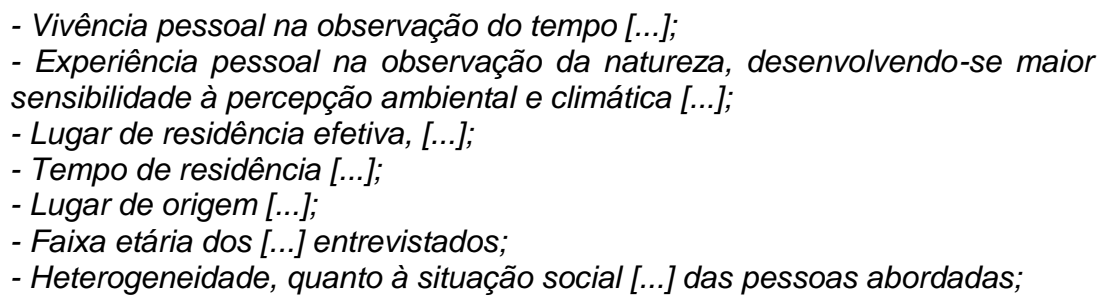

A partir disso, para a abordagem da percepção climática, foi elaborado formulário de entrevista com 23 questões (ANEXO A), baseado nos modelos aplicados por Sartori (2000) em sua tese de doutorado "Clima e Percepção".

O formulário de entrevista possui seis (6) questões fechadas que se relacionam às características pessoais, oito (8) questões abertas relacionadas ao entendimento do clima de maneira geral, quatro (4) questões abertas (16 a 19) para identificar as diferentes percepções climáticas da população urbana de Santa Cruz do Sul quanto a sucessão dos tipos de tempo. Na questão 20 explora-se se as pessoas observam alguns sinais da natureza que consideram indicativos de como estará o tempo nos próximos dias, enquanto as questões 21 e 22 tratam de como ou quanto os meios de comunicação estão influenciando na percepção do tempo pelos indivíduos. Por fim, na questão 23, aborda-se especificamente o clima da cidade de Santa Cruz do Sul em sua escala local, e ficou estabelecido que só poderia ser respondida por pessoas que residissem a mais de 20 anos na cidade, considerando o fato de que, para estabelecer um padrão climático é necessário no mínimo, 30 anos de análise dos dados das estações meteorológicas.

Dessa forma, a aplicação do formulário de entrevista se deu com a população urbana de Santa Cruz do Sul, em especial mulheres e homens que foram contatados nas ruas do centro da cidade no primeiro semestre de 2006. Foram escolhidos aleatoriamente, ao acaso, e respeitando a disponibilidade e boa vontade das pessoas em responder às perguntas ao serem abordadas, pois nem todas as pessoas aceitam responder, achando, algumas vezes, que seria um trote, ou algo ruim. Mas a grande maioria respondeu de bom grado às 
questões, achando se tratar de um bom assunto/tema a se debater. Destaca-se que "o que caracteriza o formulário é o contato face a face entre o pesquisador e o informante e ser o roteiro de perguntas preenchido pelo entrevistador no momento da entrevista" (MARCONI e LAKATOS, 1992, p. 71-96). O contato do pesquisador com o entrevistado é importante, pois além de permitir compreender a percepção da pessoa entrevistada é possível ter um olhar mais aprofundado do pesquisador em relação à realidade local, quando abordado em suas residências, e assim compreender melhor como ele percebe o tempo e o clima urbano. As entrevistas foram destinadas à pessoas adultas de várias idades, inclusive pessoas mais idosas, que pudessem indicar prováveis mudanças do tempo e do clima da cidade devido aos vários anos que ali vivem e/ou observam o tempo.

Assim, foram entrevistadas 128 pessoas no primeiro semestre de 2006 , período de maior disponibilidade da pesquisadora, sendo percorrido a pé as ruas do centro de Santa Cruz do Sul, durante todo o dia na área central do município. O número de entrevistados abordados foi considerado representativo, pois as respostas começavam a se tornar repetitivas. Apesar das condições atmosféricas de verão, as respostas perceptivas dos entrevistados não interferiram na sua percepção climática, ou seja, a época das entrevistas não mascarou a ideia de como sentem as variações de tempo ao longo do ano.

Por se tratar de um tema que estava se perdendo, foi interessante e animador notar a empolgação e envolvimento de boa parte dos entrevistados com o assunto. Estabeleceu-se espontaneamente um diálogo entre as pessoas abordadas e a pesquisadora, que entre meio a conversa fazia as perguntas naturalmente, e os entrevistados, também aproveitavam para contar histórias. $\mathrm{O}$ contato direto entre a pesquisadora e os entrevistados permitiu muitas vezes que o contato ocorresse de forma descontraída e divertida.

Com o levantamento dos dados de campo pretendeu-se discutir de forma essencialmente qualitativa o grau de percepção que as pessoas têm em relação às mudanças que ocorrem no seu entorno e constatar quais fenômenos realmente trazem significante percepção pela população da cidade. 


\section{CARACTERIZAÇÃO DA ÁREA DE ESTUDO}

O município de Santa Cruz do Sul - RS é pólo do Conselho Regional de Desenvolvimento do Vale do Rio Pardo e localiza-se na região fisiográfica denominada de Encosta Inferior do Nordeste do Rio Grande do Sul, na Depressão Periférica Sul-rio-grandense, com coordenadas 52²5'34”'Longitude Oeste e 2943'05" Latitude Sul. A cidade apresenta diferença hipsométrica significativa, pois as altitudes variam de menos $50 \mathrm{~m}$ a mais de $200 \mathrm{~m}$. Possui um território de $733,412 \mathrm{Km}^{2}$, sendo 133,40 Km² de área urbana e 661,09 Km² de rural. O município, a exemplo de outros na região, apresenta grande concentração de habitantes na cidade; a população total é de 118.374 habitantes, sendo a urbana de 105.184 (88,9\% da população total) e a rural de 13.103 (11,1\% da população total) habitantes (IBGE, 2010).

Escolheu-se para este estudo a cidade de Santa Cruz do Sul - RS, devido a sua importância na rede urbana do Estado e pela sua situação geográfica no centro do Conselho Regional de Desenvolvimento (COREDE) do Vale do Rio Pardo, que se divide em três microrregiões: a Norte, a Central e a Sul, totalizando 22 municípios. Situa-se na microrregião Central, sendo considerada uma cidade pólo desta região e também uma cidade modelo quanto a sua arborização. No mapa da Figura 1 estão representados o Brasil (A), Rio Grande do Sul (B), a área do COREDE do Vale do Rio Pardo com seus municípios (C), e a área urbana do município de Santa Cruz do Sul (D), alvo desse estudo.

Quanto aos aspectos mais físicos, nas altitudes de 100 e 200m, a lestenordeste do perímetro urbano, existe uma Área de Preservação Permanente (APA), conhecido como "Cinturão Verde", que apresenta biodiversidade muito grande, tanto no que diz respeito à flora quanto à fauna. Verificam-se, neste cinturão, as zonas de contato entre as formações geológicas Santa Maria, Botucatu e Serra Geral, envolvendo áreas de encosta e meia encosta, consideradas críticas sob o ponto de vista geotécnico e ocupacional, em que os depósitos de tálus estão em equilíbrio instável sujeitos a sofrerem escorregamentos" (WENZEL, 1996, s/p). 
A leste e a norte, a área de estudo é delimitada pelos patamares da Serra Geral, que servem de divisor de águas para os arroios que cortam a cidade, além de servir também de barreira a ventos do quadrante leste; o oeste é drenado pelo Rio Pardinho, que faz divisa com o município de Vera Cruz e, ao sul, o arroio Levis Pedroso.

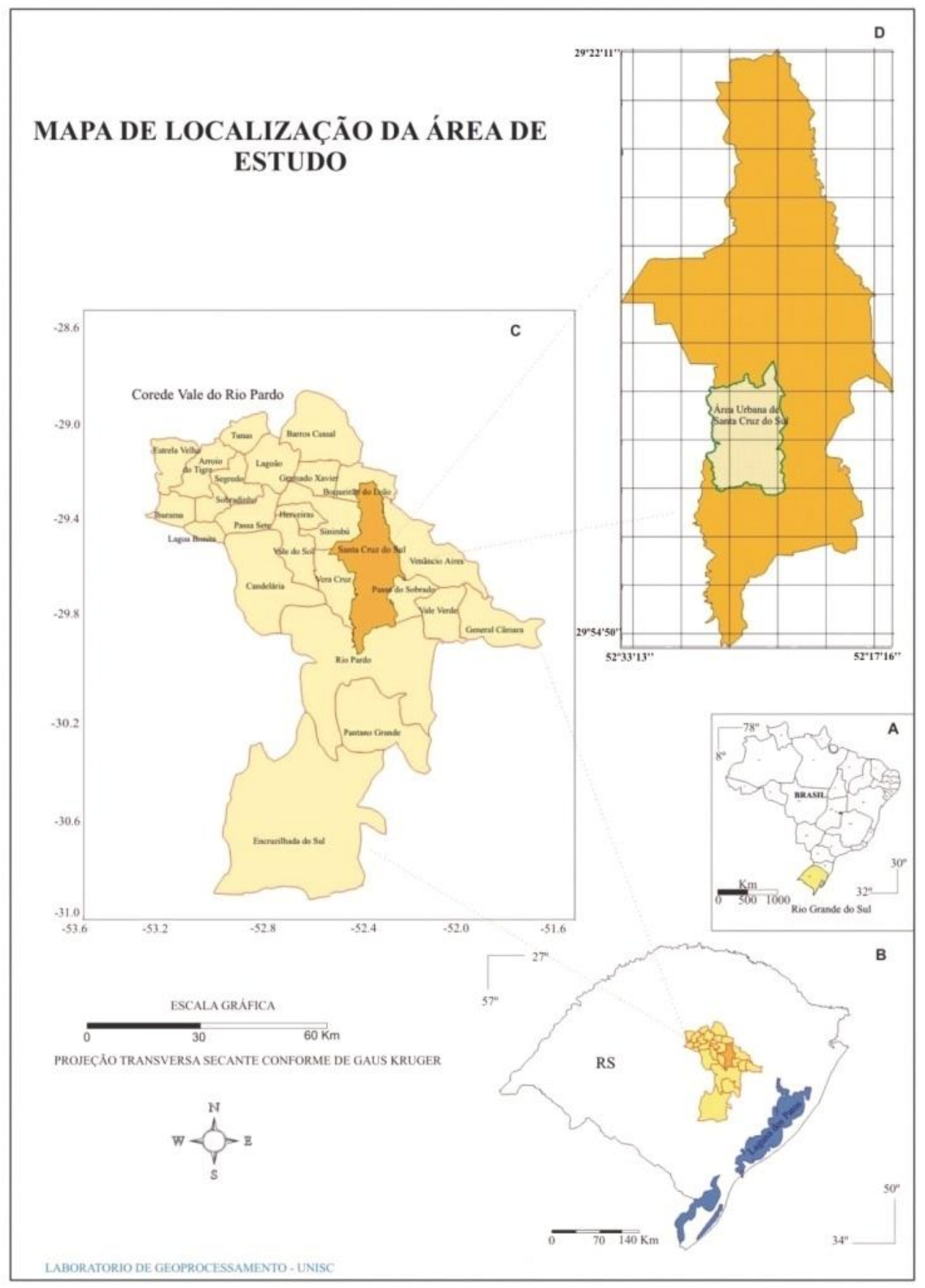

FIGURA1: Mapa de localização da área de estudo.

Fonte: Adaptado de RAUBER (2000). 
Santa Cruz do Sul está assentada sobre um relevo condicionado por certa diversidade geológica, como a Formação Botucatu, Formação Serra Geral e Formação Santa Maria. A Formação Botucatu, apesar de não estar tão presente no Vale do Rio Pardo como em outras áreas do Rio Grande do Sul, nota-se a sua presença especialmente no Morro da Cruz (Bairro Monte Verde), apresentando seqüencialmente a sobreposição das rochas vulcânicas dos derrames de lavas (basalto) do Planalto da Bacia do Paraná sobre o arenito. Destaca-se, também, a presença de vegetação em todo centro da cidade e nos bairros do seu entorno. É característico, ainda, o pátio das casas com jardins bem arborizados.

Considerando a circulação atmosférica regional e os tipos de tempo para a região de Santa Cruz do Sul, "o dinamismo de atuação das massas de ar e seus conflitos sobre a Região Sul geram condições atmosféricas que repercutem em sucessões típicas de tempo mais características e comuns" (SARTORI, 1993, p. 69). Monteiro (1971, p. 13) diz ainda que é "pela sucessão que se percebem as diferentes combinações dos elementos climáticos entre si e suas relações com os demais elementos do quadro geográfico. É a seqüência que conduz ao ritmo, e o ritmo é a essência da análise dinâmica".

Nos estudos dos comportamentos das temperaturas e precipitação apresentados por Sartori (2003) em seu texto sobre a dinâmica do clima do Rio Grande do Sul, a autora afirma serem os sistemas extratropicais atuantes 0 ano inteiro através da Massa Polar Atlântica (MPA) ou continentalizada (MPAc), Massa Polar Velha (MPV) e a Frente Polar Atlântica (FPA), que controlam a circulação secundária. Os sistemas de origem intertropical têm pouca participação na realidade climática regional e local e são representados pela Massa Tropical Atlântica (MTA), Massa Tropical Continental (MTC) e Frente Quente de Nordeste, que atuam excepcionalmente nas fases préfrontais independente da época do ano, normalmente por no máximo dois dias seguidos.

Por serem os sistemas extratropicais os que mais influenciam na região, pode-se dizer que são de extrema importância na formação do clima local do município de Santa Cruz do Sul. Baseado em Sartori (1979, 1981, 2000 e 
2003), pode-se reconhecer que predominam na região de estudo tempos associados aos Sistemas Extratropicais, tempos associados aos Sistemas Intertropicais e tempos associados às Correntes Perturbadas.

Dessa forma, a dinamicidade dos sistemas atmosféricos regionais dotados de características próprias, gera condições meteorológicas específicas através de várias combinações, definindo os diferentes tipos de tempos que são predominantes na região de estudo.

Considerando também, a temperatura na Depressão Periférica Sul-riograndense (Depressão Central), a média das máximas no verão é superior a $30^{\circ} \mathrm{C}$, podendo também chegar próximas de $40^{\circ} \mathrm{C}$, que são, com algumas exceções, tão comuns quanto nas superfícies baixas do Brasil equatorial e tropical (NIMER, 1990).

Sartori (1993) realizou um trabalho objetivando verificar as alterações nos volumes e distribuição espacial e temporal das chuvas no Estado para 72 anos divididos em três períodos (1912-1984), que possibilitou detectar a tendência na distribuição espacial através da definição das regiões climáticas no Rio Grande do Sul e consequentemente na região de Santa Cruz do Sul, que se localiza na Área 5 da Figura 2.

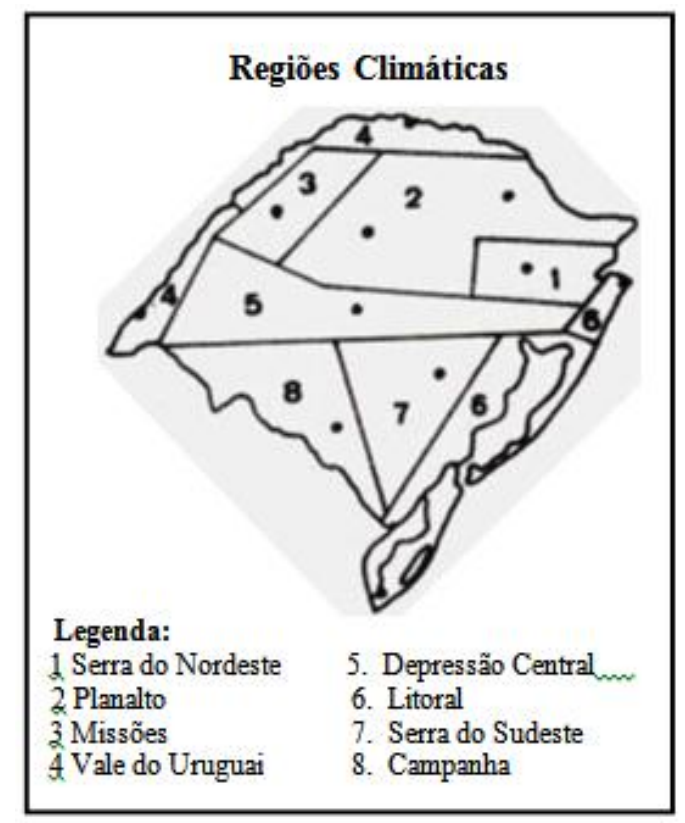

FIGURA 2 - Regiões Climáticas do Rio Grande do Sul. Fonte: SARTORI, M. da G. (1993, p. 278). 
A área da Depressão Periférica Sul-Rio-Grandense, bem como da região de Santa Cruz do Sul, apresenta características próprias, segundo informações encontradas em Sartori (1993, 2003), em relação às outras regiões climáticas do Estado como, por exemplo, as invasões periódicas do APA (Anticiclone Polar Atlântico), que acarretam invernos com temperaturas médias do mês mais frio em torno de $10^{\circ}$ a $15^{\circ} \mathrm{C}$ e a média das mínimas entre $6^{\circ}$ a $10^{\circ} \mathrm{C}$. Já nos verões, devido ao domínio eventual das massas tropicais (MTA - Massa Tropical Atlântica e MTC - Massa Tropical Continental), ou pelas Massas Polares (Polar Velha), que se modificam adquirindo novas característica devido ao aquecimento continental, a temperatura média do mês mais quente é superior a $22^{\circ} \mathrm{C}$ na maior parte do Estado, sendo que, na Depressão Central a média das máximas fica em torno de $32^{\circ} \mathrm{C}$.

No geral, as temperaturas médias anuais variam entre $18^{\circ}$ e $20^{\circ} \mathrm{C}$ na Depressão Central, e as médias das máximas/ano variam entre $20^{\circ}$ e $28^{\circ} \mathrm{C}$, enquanto que as médias mínimas/ano ficam em torno dos 9ำ e 15ํㅡ. Essa amplitude pode ser explicada pelo maior ou menor recebimento de energia solar pela superfície terrestre entre os solstícios e equinócios, além de depender da forma como as massas de ar vão atuar na região.

Em Santa Cruz do Sul, verificam-se precipitações anuais de $1.500 \mathrm{~mm}$, esse índice de precipitação pode variar para mais ou para menos, e o número médio de dias de ocorrência/frequência de chuvas durante o ano vão variar ao longo das estações.

Foi constatado que os meses mais chuvosos na maior parte do Estado são setembro e/ou outubro (primavera), exceto no litoral Sul, Serra do Sudeste e Depressão Central, que tem em junho médias pluviométricas mais altas, e o Baixo Vale do Uruguai, que registra nos meses de março e abril (Outono), os maiores índices. O mês menos chuvoso no Estado é novembro, exceto as Missões e Vale do Uruguai, onde destaca-se julho e agosto com as menores médias, além de dezembro para o Litoral, Serra do Sudeste e Campanha, e abril para o Planalto.

$\mathrm{Na}$ área de estudo, baseado nas pesquisas de Sartori (1993), ocorrem no verão, chuvas de 350 a 400mm numa faixa de leste-oeste acompanhando o 
rebordo do Planalto e onde se encontra Santa Cruz do Sul, Santa Maria e Alegrete (Depressão Central); no outono, chuvas entre 300 e $400 \mathrm{~mm}$ estendem-se no Litoral Norte e parte da Depressão Central (Santa Cruz do Sul e Porto Alegre); no inverno, o índice pluviométrico é de 400 a $450 \mathrm{~mm}$; na primavera apresenta-se com 300 a $400 \mathrm{~mm}$.

É normal no verão a umidade se apresentar menor e no inverno maior, variando entre $70 \%$ e $85 \%$. Verifica-se, também, que os ventos predominantes na região são da direção E e SE ou seja, "na Depressão Central, o vento E predomina no inverno e na primavera, enquanto no outono e no verão é o vento SE que tem maior frequência" (SARTORI, 2003, p. 42). Ainda, há alguns ventos, como os do quadrante norte que variam em velocidades (moderados a meio fortes), originando o Vento Norte que ocorre em situações pré-frontais. Já o vento Minuano, típico regional com ventos mais frios de direção predominante S e SW, ocorre sobre o domínio da MPA (Massa Polar Atlântica) quando passa pelo continente em situações pós-frontais. Nessa situação, ocorrem também os nevoeiros, que são muito freqüentes na Depressão Central, principalmente nos meses de maio a agosto que apresentam maior umidade e condições de tempo, com céu limpo que favorecem a sua formação.

\section{RESULTADOS E DISCUSSÃO}

O procedimento aleatório de abordagem dos entrevistados através do formulário de entrevistas (ANEXO A) permitiu se obter representantes das mais diferentes realidades sociais, em que os(as) 128 entrevistados(as) abordados no centro da cidade, residiam em 33 dos 45 bairros da cidade.

A tabulação das respostas às questões de 1 a 8 do formulário de entrevista revelou que das 128 pessoas contatadas, oito (8) tem menos de 20 anos (18 a 20 anos), 28 entre 21 a 30 anos, 32 pessoas de 31 a 40 anos, 16 de 41 a 50 anos, 24 de 51 a 60 anos, 11 de 61 a 70 anos e 9 pessoas com mais de 71 anos, sendo que $39 \%$ das pessoas abordadas eram do sexo masculino e $61 \%$ do sexo feminino. Dentre os entrevistados, $48 \%$ são naturais de Santa 
Cruz do Sul, os outros $52 \%$ são oriundos de municípios vizinhos e até de outros Estados do Brasil.

Quanto ao grau de escolaridade (Questão 3), apenas 1\% dos entrevistados são analfabetos, $26 \%$ constituem-se de pessoas que não terminaram o ensino fundamental, $11 \%$ possuem ensino fundamental completo ou o estão cursando, sendo que os últimos retornaram aos estudos tardiamente, $6 \%$ têm o ensino médio incompleto ou o estão cursando, $25 \%$ completaram o ensino médio, $9 \%$ dos entrevistados estão freqüentando o ensino superior, sendo que $14 \%$ já completaram a graduação em alguma área do conhecimento e atuam como profissionais de sua área, e $8 \%$ estão cursando ou concluíram uma pós-graduação.

Quanto à profissão (Questão 4), em ordem decrescente, destaca-se um maior número de pessoas aposentadas (27), professor (18), estudante (8), comerciante (7), serviços gerais (4), secretária (3), dona de casa (3), auxiliar de biblioteca (2), auxiliar administrativo (2), balconista (2), costureira (2), doméstica (2), gerente (2), industriário (2), mecânico (2), pedagoga (2), safrista (2), taxista (2), vendedor (a) (2), dentre outras menos expressivas.

Através das questões 9 e 10 do formulário de entrevista procurou-se detectar o que a população entende por tempo e clima. As respostas demonstraram que os citadinos em geral, confundem os dois conceitos, muitas vezes invertendo totalmente as respostas.

Dentre os $52 \%$ da população abordada, naturais de outros municípios a maioria disse que o clima varia em relação as suas cidades de origem (Questão 11 e 12); os oriundos dos municípios localizados no Planalto da Bacia do Paraná, no geral responderam que onde moravam não era tão quente quanto Santa Cruz do Sul, caracterizando-se por temperaturas mais amenas e mais seco e frio/quente, e destacaram que ali o tempo é úmido e quente/frio.

Os entrevistados vindos de municípios localizados na Depressão, em geral, responderam não haver muita diferença, porém uma das coisas ressaltadas é que suas cidades de origem eram mais ventiladas e o ar era mais puro, além do calor produzido pela cidade de Santa Cruz do Sul, principalmente em função da concentração de prédios, do vapor das 
fumageiras, ou seja, da atividade industrial notada principalmente por pessoas residentes ao sul da área urbana da cidade, onde se concentram as indústrias.

O que mais foi destacado na percepção climática dos entrevistados foram principalmente os elementos meteorológicos de temperatura, umidade e ventilação, que são os mais percebidos pelos sentidos humanos. Tanto que na última questão (23), na qual era enfocado: "ao longo de sua vivência na cidade de Santa Cruz do Sul, o (a) senhor (a) observou ou percebeu alguma modificação no seu clima?" As respostas mais destacadas foram que a cada ano a cidade fica mais abafada (muito quente), que as estações estão mal definidas, os invernos eram mais rigorosos, o verão está cada vez mais quente. $O$ fato de estar mais quente, alguns relacionaram ao asfalto, que também em dias de chuva e/ou enchentes dificulta a infiltração da água e aumenta o escoamento; ressaltaram também que a cidade é mais quente que o interior, e essa resposta veio principalmente de pessoas oriundas do meio rural. Responderam, também, que o verão está mais rigoroso, o inverno menos rigoroso; a poluição pela eliminação de $\mathrm{CO}_{2}$, CFC, a camada asfáltica, o lixo, a industrialização, o gradativo desmatamento do cinturão verde da cidade de Santa Cruz do Sul, entre outros.

Observa-se nessas colocações que os entrevistados percebem, além do clima, as características geomorfológicas que agravam a situação de caos na cidade.

A análise das questões 13 e 14, referentes a "que tipo de tempo que você mais gosta e não gosta no clima de Santa Cruz do Sul, respectivamente, revelou que a maioria dos entrevistados confirmaram gostar ou não de condições de tempo bem conhecidas. Como exemplos de tipos de tempo que mais gostam, os mais citados foram temperaturas amenas entre $16 / 18^{\circ} \mathrm{C}$ a $20^{\circ} \mathrm{C}$, primavera, tempo ensolarado, inverno, verão, calor/calor intenso, entre outros. Dentre os que não gostam destaca-se o calor/calor intenso, o inverno, a chuva, o frio, o verão, o tempo abafado, entre outros.

Perguntou-se também se o tipo de tempo e o clima variam mais hoje do que no passado e que justificassem a resposta (Questão 15) e a grande maioria dos entrevistados $(96 \%)$ respondeu que está havendo mais variação no 
tempo e no clima; outros ressaltaram maiores picos de calor (muito mais quente-sol mais causticante e o tempo se modifica muito mais rápido) e acham que hoje é muito mais quente que antigamente.

Outros $2 \%$ das pessoas não responderam à questão, pois não sabem ou não dão atenção ao tempo ou ao clima; $2 \%$ responderam que o tempo e 0 clima não variam, que isso é só impressão, tanto que um entrevistado acha que "no passado era mais quente e que hoje está bom!" (60 anos, masculino); outro acrescentou que o verão sempre foi quente e o inverno frio, porém com algumas variações normais de ano para ano.

Pode-se associar as opiniões da maioria (96\%) ao fato de viverem na cidade que, pelos componentes geourbanos e geoecológicos gera mais calor e cria um clima próprio - o clima urbano. Nesse sentido, alguns entrevistados demonstraram certo conhecimento, pois ressaltaram a camada asfáltica que aquece mais o ambiente, além do excesso de construções que acarreta impermeabilização do solo, propiciando alagamentos e escoamento de água que corre sobre o asfalto nas ruas das cidades e causam transtorno à população; as atividades industriais, com destaque para as fumageiras em Santa Cruz do Sul, que influenciam na atmosfera urbana e nos aspectos físicos da região.

Na questão 16 explorou-se se os entrevistados sabiam a origem (causa) da chuva e porque chove no Rio Grande do Sul e Santa Cruz do Sul. Houve vários fatores aos quais a população associou a origem da chuva. Porém, as respostas não demonstraram que as pessoas realmente entendem ou percebem a causa das chuvas.

Na questão 17 perguntou-se como a pessoa entrevistada sabia quando está para chover? Ou seja, como está o tempo antes de chover? Grande parte dos entrevistados respondeu que o tempo apresenta mudanças bruscas de temperatura, temperaturas altas/excessivas causando abafamento/"mormaço", além da umidade alta, o fato das nuvens estarem carregadas e baixas que dão um aspecto de "pesado".

O vento também foi referido como indicador de chuva, principalmente se o tempo for úmido e ventoso; houve aqueles que definiram sua direção como 
sendo vento norte, que não é tão intenso como em Santa Maria, onde é bem característico, mas também está presente em Santa Cruz do Sul. Quando o tempo está para chuva, os que sofreram algum acidente ou fizeram cirurgias sentem a mudança, pois causa dor no corpo, cansaço, moleza, agrava alguns problemas de saúde, doem cicatrizes.

Perguntou-se na questão 18 como fica o tempo depois que a chuva acaba/passa? A resposta mais citada é de que a temperatura abaixa significativamente, refresca, mas segundo os respondentes na maioria das vezes, no verão, volta o mormaço, porque estava muito quente e a chuva molhando toda a superfície quente (calçamento, asfalto, etc) a água evapora rapidamente voltando a umidade e o calor (tempo ensolarado e abafado), principalmente quando ocorrem chuvas torrenciais e rápidas. Já no inverno fica bem mais frio às vezes acompanhado de geada e com vento Minuano.

A evolução dos estados atmosféricos para indicar chuva advém da seqüência habitual do tempo, ou seja, das quatro fases de avanço das frentes e massas (fases pré-frontal, frontal, domínio polar e transicional), e a população abordada mostrou que percebe mais ou menos corretamente o que Sartori (2000, p.206) constatou quando realizou seu estudo, pois foi identificado pelos indivíduos entrevistados "...com certa facilidade, a sucessão habitual dos tipos de tempo na região em que vive, ou seja, percebe a situação pré-frontal com o vento norte , a fase frontal ao afirmar que depois esquenta chove, e o domínio polar ao definir que após a chuva o tempo fica bom, esfria ou refresca".

Apesar de não haver nenhuma bibliografia que trate da periodicidade da chuva, visou-se investigar através da questão 19 se a população urbana de Santa Cruz do Sul tem ideia de quanto tempo (dias) se passa entre uma chuva e outra. Como era de se esperar 81 pessoas não tinham a menor ideia, ou mesmo que não têm noção. Mas as respostas mais citadas, 14 pessoas responderam achar que chove em média uma vez por semana e outras 12 de 15 em 15 dias, seguido da colocação de quatro pessoas que afirmaram que no inverno a chuva é mais freqüente, isso porque chove menos em um período maior. 
Outros fazem a ligação das chuvas à mudança das fases da lua e disseram que chove de 20 a 30 dias, dando o exemplo dessa pesquisa, pois a condição de tempo nos dias de trabalho de campo era de chuva e não chovia a mais ou menos esse período.

Na questão vinte (20) investigou-se "Que sinais a natureza apresenta para indicar o comportamento do tempo nos próximos dias? Ou seja, o(a) senhor (a) sabe quando vai ou não chover, quando vai continuar a seca ou a enchente, quando vai fazer mais frio ou mais calor, se o inverno ou o verão vai ser mais seco ou mais chuvoso, por exemplo?".

Foram obtidas várias respostas referentes a essa questão que foram organizadas em seis grupos: o primeiro grupo diz respeito aos sinais baseados nas reações dos animais para indicar chuva; o segundo, refere-se aos sinais das plantas que indicam quando está para chuva; o terceiro apresenta os sinais do tempo para indicar chuva; o quarto grupo (TABELA 1) lista-se os sinais do corpo; o quinto grupo contém os sinais pelas mudanças de fase da lua e de dias dos meses; no sexto grupo (TABELA 2) são apresentados os sinais que indicam tempo bom/seco/estiagem ou frio. A explicação para os ditados populares citados é baseada principalmente em Sartori (2000).

O primeiro grupo de respostas diz respeito aos sinais a partir dos animais para indicar chuva. Entre eles encontram-se os sapos (do gênero Bufo). Apresentam pele fina necessitando viver em lugares úmidos para se protegerem, porque sua pele não segura água. Os sapos (uma ocorrência) são sensíveis à pressão atmosférica e a umidade. Quando a pressão abaixa, devido à chegada de frentes frias ou instabilidades tropicais no Rio Grande do Sul (fase frontal), mexe com o sistema sensorial receptor, fazendo com que os sapos e também rãs (gênero Rana) coachem muito, indicando chuva próxima.

Os bugios (três ocorrências), símios platirrinos da família dos cebídeos de gênero Allouatta, são também chamados de barbados, por possuir o pescoço muito avolumado, que funciona como caixa de ressonância produzindo o conhecido "ronco". São sensíveis à pressão atmosférica, quando ela muda drasticamente (fase frontal) roncam insistentemente anunciando chuva. 
A saracura (quatro ocorrências), ave gruforme da família dos relídeos, passa o dia escondida na vegetação saindo somente à tarde para se alimentar, canta ao entardecer, se cantar fora desse horário é porque pressente a mudança de tempo por ser sensível a pressão atmosférica.

As formigas-cortadeiras (três ocorrências) são insetos himenópteros, da família dos formicídios. São conhecidas por estarem em constante atividade de carregar as folhas cortadas e outras substâncias sob condições de tempo bom para o seu armazenamento e cultivo do fungo na qual lhes serve de alimento. Quando o ritmo de sua atividade aumenta é sinal de que pressentem o mau tempo, trabalhando mais para se prevenirem.

O inseto himenópteros, da família dos dorelídeos, conhecida como formiga correição (duas ocorrências), diferente das cortadeiras, não armazena seu alimento, são predadoras e realizam grandes migrações durante horas ou dias em busca de alimento (outros animais). Também aumentam sua atividade quando pressentem a mudança de tempo para chuva com o fim de passar os dias chuvosos.

O comportamento do joão-de-barro (uma ocorrência), também citado, é uma ave passeriformes, da família dos furnarídeos, e sua área de vivência corresponde de 100 a $200 \mathrm{~m}^{2}$ por casal. Por isso ele conhece muito bem onde vive, inclusive o clima em micro e mesoescala. Quando o joão-de-barro canta, independentemente das condições de tempo, é sinal de tempo bom.

O burro (duas ocorrências) é outro animal que reage às mudanças de pressão e de calor. Quando há aquecimento frontal, o burro começa a se mexer, rolando no chão anunciando chuva e isso se dá provavelmente devido ao seu suor espesso/engraxado, que faz com que se esfregue para se limpar. Outros animais como bois, cavalos, etc (duas ocorrências), também pressentem a mudança de tempo, por serem sensíveis a pressão atmosférica; quando o tempo muda eles se reúnem para protegerem-se e procuram abrigo. Quando o gado está espalhado pastando é sinal de tempo bom.

Os pássaros quando voam baixo e agitados (três ocorrências) pressentem a mudança de tempo. Eles são sensíveis à pressão atmosférica que abaixa quando ocorre fase frontal, anunciando a chegada da chuva. A 
mesma coisa acontece com a movimentação das moscas e mosquitos (quatro ocorrências).

Ao contrário da saracura, o passarinho tico-tico (uma ocorrência), canta durante o dia e se recolhe à noite. Quando ele passar a cantar durante a noite é sinal de chuva, pois sente as mudanças atmosféricas de pressão e temperatura.

Outro animal observado pelos entrevistados é a galinha (uma ocorrência) que ao se "pentear" (limpando e ajeitando suas penas) anuncia chuva. Esse fato deve estar relacionado também com o aquecimento frontal, pois a penugem da galinha propicia maior suor em seu corpo e desajeito em suas penas, por isso ela se penteia. Por fim, as formiguinhas de asa (quatro ocorrências), sempre que entram dentro das casas procurando abrigo é sinal de chuva, pois sentem as mudanças de pressão e temperatura bem característica da fase frontal e buscam proteção.

O segundo grupo de sinais da natureza para previsão do tempo referese ao comportamento das plantas com sinais relacionados com condições de tempo bom seguido de maior aquecimento e queda da pressão atmosférica. Situações assim propiciam as flores se abrirem e quando abrem todas as flores da "arvorezinha do tempo" (duas ocorrências), assim intitulada pelos entrevistados, indica chuva. $O$ angiquinho floresce (duas ocorrências) um ou dois dias antes da chuva, tempo indicado para ocorrer a precipitação correspondente ao tempo que a frente leva para avançar sobre a região.

Devido ao aquecimento e a queda de pressão, plantas (quatro ocorrências) e flores (margarida) murcham (duas ocorrências) indicando que no máximo em dois dias choverá. Semelhante e pelo mesmo motivo, as árvores (uma ocorrência) também torcem suas folhas para indicar chuva. Mas, como as plantas citadas não representam toda flora entende-se que somente certas espécies de árvores e flores apresentam reações interpretadas como indicadoras de chuva.

O terceiro grupo de sinais refere-se às condições atmosféricas para indicar chuva, destacando-se entre as referências a umidade na cerâmica/ pisos/ sal/ geladeira/ banheiro/ paredes/ no ar (pano de enxugar louça molha 
mais rápido (vinte e quatro ocorrências); nuvens rabo de galo em dois ou três dias antes da chuva (dezenove ocorrências); Vento Norte: chove no dia ou depois de três dias/ Tempestade (dezessete ocorrências).

As situações pré-frontais também apresentam nuvens rabo de galo, também citados entre os entrevistados. Os rabos-de-galo são nuvens cirros (cirrus-cumulos e alto-cumulos) que apresentam o céu pedrento ou encarneirado ou em forma de escama de peixe. As

\footnotetext{
... primeiras e mais altas, que prenunciam a aproximação de frentes (FPA), são nuvens cirros, seguidas de nuvens médias do tipo alto-estratos e altocumulos. Daí indicarem chuva para breve, com vento ou não, dependendo da frontogênese [...] como nas frases pré-frontais os ventos são normalmente do quadrante norte, a explicação também é válida para a citação que envolve 0 vento norte (SARTORI, 2005, p. 12).
}

As citações a respeito da umidade relativa do ar tem a ver com situações pré-frontais, acarretando aumento da temperatura e diminuição da pressão atmosférica, mas também pode estar relacionado à inversão térmica que ocorre à noite devido a irradiação terrestre ser muito intensa, fazendo com que o ar próximo da superfície se resfrie rapidamente em contato com o solo, especialmente se o ar estiver calmo e o céu limpo. O fenômeno das "inversões ocorrem desde os habituais resfriamentos noturnos até fenômenos mais complexos das camadas de ar nos limites da troposfera, passando pela termodinâmica específica do organismo humano, segundo demonstram muitos estudos sobre a ilha de calor urbana" (MENDONÇA, 2003, p. 51).

Outros sinais menos citados como indicadoras de chuva, mas que não deixam de ganhar importância são: "nuvens com manchas brancas; nuvens escuras: vento com muito frio; nuvens embolotadas/carneirinhos/escama de peixe (sete ocorrências); tempo amarelado (duas ocorrências); avermelhado no céu (quatro ocorrências); céu branco no horizonte (uma ocorrência); horizonte pouco visível (esfumaçado) (uma ocorrência); quando não tem estrela: chuva (duas ocorrências); nuvens brancas acinzentadas: chuva (duas ocorrências); no inverno, neblina constante nos morros (uma ocorrência); nuvens que vão para o sul (uma ocorrência); quando passa um avião a jato, se a fumaça se 
abrir é sinal de chuva (duas ocorrências); círculo em volta do sol (uma ocorrência); arco com cerração na lua: chove no máximo oito dias (uma ocorrência); cerração/borda na lua (quatro ocorrências); quando o sol nascer vermelho em 24 horas chove (uma ocorrência); baixo nível de água dos rios (anormal): em um dia ou uma semana chove (uma ocorrência); propagação de sons distantes: chuva (cinco ocorrências); cheiros se propagam mais: chuva (uma ocorrência).

O quarto grupo compõe-se dos sinais no corpo que indicam chuva (TABELA 1). Ocorrem em situações frontais, na qual o aquecimento que antecede a entrada da frente, assim como o declínio da pressão atmosférica, declínio acentuado da umidade relativa, ventos do quadrante norte e aumento gradativo da nebulosidade, causam desconforto e mal estar em pessoas mais tempo-sensitivas. É durante a inversão térmica que aumenta as queixas em relação à asma, dores abdominais e problemas de natureza psicológica e psiquiátrica. Já quando a temperatura e umidade absoluta do ar se elevam em relação ao dia anterior, ocorrem queixas relacionadas à asma, ao coração e circulação sanguínea, além de sintomas de febre. Os efeitos poderão ser ainda maiores se essa condição de tempo ocorrer fora de sua estação habitual (SARTORI, 2000, p. 81).

No quinto grupo encontra-se observações dos dias do ano ou meses que indicam as condições de tempo nos próximos dias ou meses. Como exemplo pode-se destacar a dos primeiros 12 dias de janeiro, que revelam como o tempo se comportará em cada mês do ano (cinco ocorrências), ou seja, as condições de tempo de cada dia correspondem ao que acontecerá com as chuvas nos 12 meses do ano. Outros exemplos são: em julho, se chover na primeira terça-feira da semana, chove o mês inteiro (uma ocorrência); se chover na primeira terça-feira de agosto, chove mais ainda (uma ocorrência); se chover muito no dia de São Pedro, indica ano de abundância de chuva (uma ocorrência); quando muda da lua crescente para a lua cheia, mas se não chove na mudança fica mais oito dias sem chuva (uma ocorrência); se estiver chovendo antes da lua cheia entrar depois é período de estiagem (uma ocorrência). 
TABELA 1 - Sinais que o corpo apresenta para indicar chuva segundo a população urbana de Santa Cruz do Sul.

\begin{tabular}{l|c}
\multicolumn{1}{c|}{$\begin{array}{c}\text { Reações fisiológicas no corpo que indicam chuva ou } \\
\text { estiagem. }\end{array}$} & $\begin{array}{c}\text { No de } \\
\text { referências }\end{array}$ \\
\hline Dor em cicatrizes/cirurgias: chuva. & 10 \\
\hline Dor nas juntas, principalmente para idosos: chuva. & 4 \\
\hline Dor no corpo: chuva & 2 \\
\hline Crianças e pessoas mais agitadas: chuva. & 2 \\
\hline Cansaço: chuva. & 2 \\
\hline Mal estar e queda de pressão: chuva. & 3 \\
\hline Moleza no corpo: chuva. & 1 \\
\hline Sente o corpo mais pesado: chuva. & 2 \\
\hline Dor nos ossos: chuva. & 1 \\
\hline Pé inchado: chuva. & 2 \\
\hline Coceira em cirurgia: chuva. & 1 \\
\hline $\begin{array}{l}\text { Quando está para chover, há influencia sobre o organismo } \\
\text { das pessoas, principalmente idosos. }\end{array}$ & 3 \\
\hline $\begin{array}{l}\text { Quando quebrou um osso (perna joelho,etc.), sente dor antes } \\
\text { da chuva. }\end{array}$ & 1 \\
\hline $\begin{array}{l}\text { Cabelos não se arrumam, e cabelos cacheados/crespos } \\
\text { ficam mais enrolados: chuva. }\end{array}$ & \\
\hline
\end{tabular}

Fonte dos dados: Trabalho de campo.

Org.: RUOSO, Diamar.

Por fim, o sexto grupo compõe-se de sinais que indicam se o tempo será bom, se fará seca ou frio, menos conhecidos (TABELA 2), mas que não deixam de ter sua importância perante a população.

Através das questões 21 e 22, investigou-se como a mídia estava influenciando na percepção das pessoas. Ficou claro que a maioria das pessoas acreditam e confiam na previsão do tempo dos serviços de meteorologia, mas deve-se ressaltar que dentre essa maioria estão aqueles que observam muito bem a natureza. Então, confiar na previsão do tempo, não quer dizer que a população urbana de Santa Cruz do Sul não atente para a natureza, mas podem estar realizando as duas formas de prognóstico. O que se pode afirmar pelas entrevistas é que uma minoria não observa o tempo, diz que não dá para prever. 
TABELA 2 - Sinais que o tempo apresenta para indicar seca/estiagem, frio, segundo a população urbana de Santa Cruz do Sul.

Sinais do tempo para indicarem tempo bom, seco/estiagem ou frio.

\begin{tabular}{l|c}
\multicolumn{1}{c|}{$\begin{array}{c}\text { Sinais do tempo para indicarem tempo bom, } \\
\text { seco/estiagem ou frio. }\end{array}$} & $\begin{array}{c}\text { № de } \\
\text { referências }\end{array}$ \\
\hline $\begin{array}{l}\text { Vento nascente (de leste): período de seca por causa da } \\
\text { ressaca do mar. }\end{array}$ & 1 \\
\hline Vento fresco e de finados: seca. & 2 \\
\hline Vento do sul: seca e frio. & 2 \\
\hline Cerração baixa: sol que racha. & 6 \\
\hline Borda ao redor da lua: seca. & 2 \\
\hline Quando o sol nasce vermelho: seca. & 2 \\
\hline Sol bem avermelhado: seca. & 3 \\
\hline Pôr-do-sol avermelhado: sinal de seca/estiagem. & 5 \\
\hline Horizonte amarelado: tempo bom. & 1 \\
\hline Céu bem azul clarinho: a chuva está longe. & 1 \\
\hline Nuvens escuras: vento com muito frio. & 1 \\
\hline Nuvens ficam mais leves quando vai parar de chover. & 1 \\
\hline Nuvens altas: não chove & 1 \\
\hline Verão muito quente: inverno muito frio (gelado). & 3 \\
\hline Quando olhar o Rio Pardinho e observar que as plantas & 1 \\
\hline estão com um aspecto de murcho/seco: é sinal de seca. & \\
\hline Cigarra cantando sem parar: seca. & 2 \\
\hline Fon
\end{tabular}

Fonte de dados: Trabalho de campo.

Org.: RUOSO, Diamar.

Realmente, o exagero e o fascínio proporcionado principalmente pela televisão inferem na percepção humana do clima, principalmente quando colocam cenas que emocionam com imagens de destruição, sofrimento, aflição e morte, como exemplo da seca do nordeste e as enchentes no sudeste, que foram citadas constantemente como exemplo em respostas a várias questões.

\section{CONSIDERAÇÕES FINAIS}

Neste trabalho realizado em Santa Cruz do Sul/RS, buscou-se contribuir efetivamente para o desenvolvimento da ciência geográfica, em especial nos estudos referentes à percepção ambiental e climática que ainda é pouco explorada no país. Apesar de existir o método que norteou essa pesquisa, ou seja, a metodologia proposta por Sartori (2000) referente a abordagem da percepção climática. 
Apesar de a pesquisa ter se realizado com a população urbana, é considerável o seu conhecimento sobre o tempo, fato que está ligado a suas origens, pois verificou-se que boa parte dos entrevistados eram de origem de municípios mais interioranos, muitos da área rural, que vieram à cidade de Santa Cruz do Sul em busca de empregos, estudos e outros. Isso permitiu delinear o perfil da população e suas formas de organizar e olhar a paisagem vivida, sob diversos pontos de vista.

Algumas das pessoas entrevistadas revelaram-se claramente temposensitivas, pois percebem mudanças psicofisiológicas em seu organismo, como dor em cicatrizes de cirurgias, fraturas antigas, e doenças cujos sintomas se agravam sob certas condições de tempo.

A abordagem perceptiva adotada para o trabalho mostrou-se eficiente aos objetivos propostos, pois as respostas ao instrumento de pesquisa, representado pelo formulário de entrevista revelaram a sensação e percepção dos indivíduos quanto ao tempo e ao clima as reações humanas às condições de temperatura que levam ao bem estar e/ou desconforto ambiental, bem como demonstraram que algumas pessoas praticam a observação e atenção aos fatos naturais, especialmente através da visão e audição. No conjunto, resultaram em uma autêntica percepção/cognição ambiental, considerando-se também a influência dos fatores culturais, históricos e ambientais.

Por fim, deve-se destacar a importância de estudar e resgatar o conhecimento popular, pois é importante não ignorar hipóteses que possam surgir de pequenas observações vindas do conhecimento empírico, muito rico em experiências e em espaço vivido. 


\section{REFERÊNCIAS BIBLIOGRÁFICAS}

BUTTIMER, A. Apreendendo o Dinamismo do Mundo Vivido. In: CHRISTOFOLETTI, Perspectivas da Geografia. DIFEL, ed. 2ª , S. Paulo.1985.

CHRISTOFOLETTI, A. Correntes do pensamento geográfico. $<$ http://www.facil.pop.com.br/INcorrentesgeograficas.htm>. Acesso em: 29 jul. 2005.

ENTRIKIN, Nicholas. Contemporary humanism in geography. Annals Association of American de Geographers, v.66, n.4,pp. 615-132. Dec. 1976.

FAGGIONATO, S. Percepção Ambiental. Disponível em:

$<$ http://ambientes.ambientebrasil.com.br/educacao/artigos/percepcao_ambienta I.html >. Acesso em: 26 set. 2005.

INSTITUDO DE GEOGRAFIA E ESTATÍSTICA - IBGE, 2010.

MACHADO, L. M. C. P. 1988. A Serra do Mar Paulista: Um Estudo de Paisagem Valorizada. Tese de Doutorado. UNESP. Rio Claro-SP, 1988.

MACHADO, L. M. C. P. Paisagem, Ação, Percepção e Cognição. In: 3o Encontro Interdisciplinar sobre o Estudo da Paisagem. Rio Claro. Anais. Rio Claro: UNESP, 1998. p. 01 - 04.

MARCONI, M. de A.; LAKATOS, E. M. Metodologia do trabalho científico. 4 ed. São Paulo: Atlas, 1992.

MENDONÇA, F. Clima e Planejamento Urbano em Londrina: Proposição meteorológica e de intervenção urbana a partir do estudo do campo termohigrométrico. In: MONTEIRO, C. A. de F; MENDONÇA, F. Clima Urbano. São Paulo: Ed. Contexto. 2003.

MONTEIRO, C.A. de F. Análise rítmica em climatologia. In: Climatologia, n. 1, São Paulo, lgeog/USP, 1971.

C. A. F. Teoria e Clima Urbano. São Paulo, Instituto de Geografia da USP, 1976. Série "Teses e Monografias" n²5.

, C. A.F. A frente polar atlântica e as chuvas de inverno na fachada sul-oriental do Brasil. 1969. 68f. Tese (Doutorado em Geografia) Universidade de São Paulo, São Paulo, 1969.

NIMER, E. Região Sul. IN: Geografia do Brasil. Fundação Instituto Brasileiro de Geografia e Estatística, Diretoria de Geociências. Rio de Janeiro: IBGE, 1990.

RAUBER, A. (org. dos mapas). Laboratório de Geoprocessamento. Universidade de Santa Cruz do Sul - UNISC, 2000. 
RUOSO, Diamar. O CLIMA DE SANTA CRUZ DO SUL - RS E A PERCEPÇÃO CLIMÁTICA DA POPULAÇÃO URBANA. Dissertação de Mestrado - Mestrado em Geografia. Universidade Federal de Santa Maria UFSM. Santa Maria, RS, 2007. 171p.

SARTORI, M. da G. B. O clima de Santa Maria, RS: do Regional ao Urbano. 1979. 150f. Mestrado (Mestrado em Geografia) - Universidade de São Paulo, São Paulo. 1979.

, M. da G. B. A circulação atmosférica regional e as famílias de tipos de tempo identificadas na região central do Rio Grande do Sul. Revista Ciência e Natura. Santa Maria. 3, 1981, 101 - 110.

, M. da G. B. A circulação atmosférica regional e os principais tipos de sucessão do tempo no inverno do Rio Grande do Sul. Revista Ciência e Natura. Santa Maria. 15, 1993, p. 69 - 93.

, M. da G. B. Clima e Percepção Vol.1. Tese de doutorado em Geografia. São Paulo, 2000.

M. da G. B. A dinâmica do clima do RS: Indução empírica e conhecimento científico. Revista Terra Livre. São Paulo. Ano 19 - Vol 1n. 20, 2003 (jan/jul).

RELPH, E. A paisagem urbana moderna. Edições 70. Lisboa, 1987.

SILVEIRA, R. L. L. da; HERMANN, E. As cidades e a urbanização do Vale do Rio Pardo. In: VOGT, Olgário Paulo; SILVEIRA, Rogério Leandro Lima da (orgs). Vale do Rio Pardo: (re)conhecendo a região. Santa Cruz do Sul: Ed. Da Universidade - EDUNISC, 2001.

TUAN, Yi-Fu. Topofilia: um estudo da percepção, atitudes e valores do meio ambiente. Tradução prefácio e notas: Lívia de Oliveira. São Paulo: DIFEL, 1980.

WENZEL, J. A. Mapeamento geológico estrutural geotécnico da zona urbana de Santa Cruz do Sul visando obter infoemações básicas ao planejamento integrado. Universidade de Santa Cruz do Sul, 1996. 
ANEXO A - FORMULÁRIO DE ENTREVISTA

Percepção do clima urbano de Santa Cruz do Sul/RS

DATA:

Etnia:

1. Idade: $\square$ Jovem $\square$ Adulto_

$\square$ ldoso

2. Sexo: $\square$ Feminino $\square$ Masculino

3. Grau de Escolaridade:

$\square$ Analfabeto $\square$ Ens. Fund. I. $\square$ Ens. Fund. C. $\square$ Ens. Méd. I.

$\square$ Ens. Méd. C. $\square$ Ens. Sup. I. $\square$ Ens. Sup. C. $\square$ Pós - Graduação

4. Profissão:

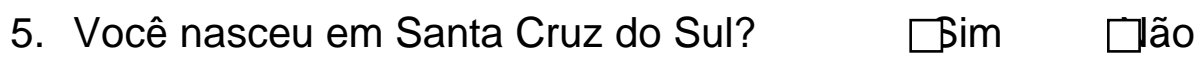

6. Onde você nasceu (cidade/estado)?

7. Quanto tempo reside na cidade de Santa Cruz do Sul?

8. Qual o bairro que você reside?

9. O que é clima para você?

10.0 que é tempo meteorológico para você?

11.0 clima de sua região de nascimento é muito diferente do clima da região de Santa Cruz do Sul?
$\square \operatorname{Sim}$
$\square$ Não
$\square$ Não sabe
$\square$ पão Lembra

12. Qual a diferença de sua cidade de origem e Santa Cruz do Sul que você julga mais importante?

13. Que tipo de tempo você não gosta no clima de Santa Cruz do Sul?

14. Que tipo de tempo você mais gosta no clima de Santa Cruz do Sul? 
15. Você acha que o tipo de tempo e o clima variam mais hoje do que no passado?

$\square$ Sim.Porque?

16. Você sabe qual a origem (causa) da chuva? Porque chove no Rio Grande do Sul e Santa Cruz do Sul?

17. Como você sabe quando está para chover? Ou seja, como está o tempo antes de chover?

18. Como fica o tempo depois que a chuva acaba/passa?

19. Você tem idéia de quanto tempo (dias) se passa em média entre uma chuva e outra?

20. Que sinais a natureza apresenta para indicar o comportamento do tempo nos próximos dias? ou seja, como o(a) senhor(a) sabe quando vai ou não chover, quando vai continuar a seca ou a enchente, quando vai fazer mais frio ou mais calor, se o inverno ou o verão vai ser mais seco ou mais chuvoso, por exemplo?

21. Confia mais no que você mesmo observa da natureza ou na previsão oficial do tempo?

22. Você acredita na previsão do tempo apresentada na TV, rádios e jornais?Porquê?

23. A longo de sua vivência na cidade de Santa Cruz do Sul, o(a) senhor(a) observou ou percebeu alguma modificação no seu clima? Fale a respeito? 